\title{
An audit of pulmonary rehabilitation program
}

This article was published in the following Dove Press journal:

Clinical Audit

18 August 2016

Number of times this article has been viewed

\author{
Amanda A McNaughton ${ }^{1,2}$ \\ Mark Weatherall ${ }^{3}$ \\ Gayle Williams ${ }^{4}$ \\ Dionne Delacey ${ }^{4}$ \\ Carol George ${ }^{4}$ \\ Richard Beasley ${ }^{2}$ \\ 'Department of Respiratory Medicine, \\ Capital and Coast District Health \\ Board, ${ }^{2}$ Medical Research Institute \\ of New Zealand, ${ }^{3}$ Wellington School \\ of Medicine \& Health Sciences, \\ University of Otago, ${ }^{4}$ Community \\ Health Services, Capital and Coast \\ District Health Board, Wellington, \\ New Zealand
}

Aim: Pulmonary rehabilitation (PR) is effective and recommended for all symptomatic patients with chronic obstructive pulmonary disease (COPD). An audit from the UK highlighted issues of low referral rates, limited uptake, and low completion rates. We wished to explore whether these issues applied in the PR service in Wellington, New Zealand, and to assess attainment of British Thoracic Society Quality Standards.

Methods: Retrospective cohort study of a PR program for a calendar year in a secondary care hospital by case note review for demographics, diagnosis, spirometry, referral source, attendance, and 6-minute walk test (6MWT) at baseline and program exit. Attendance rates by sex, ethnicity, smoking status, age, percent predicted forced expiratory volume in 1 second (FEV1\%), and baseline 6MWT are described and associations estimated by Poisson regression.

Results: In the year of the cohort study, 323 patients were referred, which represents only about $2 \%$ of the estimated prevalent population of COPD in the hospital catchment. Of these, $256(80 \%)$ attended at least one session. Almost half (46\%) completed $75 \%$ or more sessions. Lower session attendance was significantly associated with ethnicity, $P=0.002$, with European compared to Māori relative rate of 1.34 (95\% confidence interval [CI] 1.07 to 1.73) and compared to Pacific Island 1.82 (95\% CI 1.18 to 2.80); and with smoking, with current smokers less likely to attend than ex-smokers, relative rate 0.67 (95\% CI 0.49 to 0.92 ), $P=0.031$. There was no association between attendance rates and sex, age, FEV1\%, and a weak association with baseline 6MWT. The 6MWT improved from baseline by 35 meters (95\% CI 25.0 to 45.6 meters), $P<0.001$. Areas for improvement in the quality standards were earlier PR attendance after an acute exacerbation of COPD, identification of all those with acute exacerbation of COPD in hospital, and more consistent completion of health status instruments.

Conclusion: Completion rates for PR are similar to those in the UK audits. The program could be improved by encouraging referral, a shorter rolling program of hospital-based PR to improve attendance rates, and better ways of delivering PR to current smokers and people of all ethnicities. Keywords: pulmonary rehabilitation, audit, referral, attendance, smokers, ethnicity, quality standards, New Zealand

\section{Introduction}

Chronic obstructive pulmonary disease (COPD) is a highly prevalent disease characterized by persistent airflow limitation, which is usually progressive. Exacerbations and comorbidities contribute to the overall severity in individual patients. Common symptoms include progressive breathlessness, cough and sputum production, functional limitations, social isolation and anxiety, and depression. ${ }^{1,2}$ COPD has a substantial impact on the health of New Zealanders, affecting up to $15 \%$ of the adult population aged $>40$ years. ${ }^{3}$
Correspondence: Amanda A McNaughton Department of Respiratory Medicine, Wellington Hospital, Riddiford Street, Wellington, 602I, New Zealand Email amanda.mcnaughton@ccdhb.org.nz 
Pulmonary rehabilitation (PR) is one of the most effective therapies for COPD. It improves quality of life, exercise tolerance, and breathlessness. ${ }^{4}$ Furthermore, alongside smoking cessation and influenza immunization, it is considered one of the most cost-effective treatments for COPD. ${ }^{5} \mathrm{PR}$ also reduces health care resource utilization. ${ }^{6}$ All respiratory medicine professional bodies (American Thoracic Society [ATS], European Respiratory Society [ERS], British Thoracic Society [BTS], and Thoracic Society Australia \& New Zealand) recommend PR for symptomatic patients with COPD and other chronic lung disease, and have published evidence-based guidelines..$^{7-9}$ BTS has produced quality standards. ${ }^{10}$ Thoracic Society Australia \& New Zealand produces a toolkit (but not quality standards) to guide PR program implementation. ${ }^{9}$

International survey data as well as audits from New Zealand and the $\mathrm{UK}^{11-13}$ show that this effective therapy is greatly underutilized. Increasing uptake of PR, as well as augmenting and sustaining the benefits of PR are much needed topics of research, as recommended by ATS/ERS and others. ${ }^{14,15}$

The aim of this audit was to assess the resources, organization, and performance of the Capital and Coast District Health Board (CCDHB) PR program. We wished to explore referral rates, uptake, completion rates, and outcome measures for this program and compare these with recently published UK audits, as well as assessing attainment against the BTS quality standards. ${ }^{10,13}$

\section{Methods}

CCDHB is a publicly funded secondary and tertiary level hospital service organization serving a catchment population of 300,000 people in Wellington, New Zealand, of whom 105,000 are aged over 45 years. A comprehensive casefinding study of COPD in the Wellington region estimated the prevalence of COPD is $14 \%$ in this age group 3 so that there are likely to be at least 14,700 people with COPD in the catchment population. Outpatient PR programs are run at three sites: Wellington Hospital, Kenepuru Hospital, and Kapiti Health Centre. The PR program runs for 8 weeks, with two classes a week for a total of 16 classes. Each class lasts one and a half hours and comprises 45 minutes of individualized exercise training and 30 minutes of group education. The courses are run by trained respiratory nurses and physiotherapists, although some education sessions are also delivered by social workers, pharmacists, palliative care nurses, and respiratory physicians. Six courses are run each year, as cohorts, but with some rolling flexibility to allow early attendance of patients on the waiting list, if spaces arise due to nonattendance.
Data definitions for the audit items were agreed. Data for this study were obtained from PR program reports and hospital records for each individual referred for PR between April 1, 2014 and April 1, 2015. The pro forma for data collation reflected the Royal College of Physicians UK national COPD audit. ${ }^{13}$ Demography, diagnosis, smoking history and severity of lung disease (spirometry if available), and time from recent exacerbation to PR first attendance were collected from hospital records. Spirometry was not routinely measured at PR and available in hospital records for only 144 patients (56\%). Referral source, reason for declining PR, attendance, baseline, and program exit 6-minute walk test (6MWT) results were obtained from PR program reports. PR program data were collected prospectively (GW, DD), collated into an electronic database with the hospital data and checked for accuracy (CG, AM), and analyzed (MW, AM). The audit was registered at CCDHB and the Capital \& Coast District Health Board Research Governance Group confirmed that formal ethical approval was not required. Because this was an audit written informed patient consent was not obtained.

As well as describing our cohort, we wished to see if sex, ethnicity, smoking status, age, percent predicted forced expiratory volume in 1 second (FEV1\%), and initial 6MWT predicted the number of attendances at PR and the change in 6MWT for those completing two measurements.

Simple data descriptions are shown. Rank-correlation coefficients are used to compare attendance at PR with continuous predictors and Poisson regression with an offset for the total number of possible visits is used to examine the association between the number of attendances with the other variables. The number of attendances was over-dispersed and a scaled deviance was used to adjust for this. The difference in 6MWT was compared with a paired $t$-test. SAS version 9.4 was used (SAS Institute Inc., Cary, NC, USA).

\section{Results}

During the 1-year audit period, 323 patients were referred to the PR program, of whom 67 declined to attend and of those who agreed to attend, there was attendance data available for 226/256 (88\%). Of the 67 patients who declined PR, 43 (64\%) gave a reason, and these reasons included: not interested (44\%), working fulltime (16\%), too sick (14\%), social issues, for example, childcare, caring for partner (9\%), and a clash with other classes (5\%). Transport was given as a reason for only $5 \%$. The 323 patients referred are $\sim 2 \%$ of the estimated population with COPD in the catchment region of CCDHB. The patients are described in Table 1. Of these participants, $68(27 \%)$ had completed one or more PR 
Table I Characteristics of the 256 patients who attended the PR program

\begin{tabular}{llll}
\hline Variable & Mean (SD) & Median (IQR) & Min to max \\
\hline Age (years) N=256 & $71.8(I I .0)$ & $73.2(65.0$ to 79.7$)$ & 25.9 to 96.3 \\
Attendance count & $10.2(5.3)$ & $12(7$ to I5) & 0 to I6 \\
$\mathrm{N}=226$ & & & \\
Attendance out of & $64.0(32.9)$ & $75.0(43.8$ to 93.8$)$ & 0 to 100 \\
possible I6 sessions & & & \\
(\%) N=226 & & & \\
FEVI\% N=I44 & $52.2(22.5)$ & $47.5(36.5$ to 70.0$)$ & 12.0 to II 3.0 \\
Variable & & $\mathbf{n} / 256(\%)$ & \\
Male sex & & $108(42.2)$ & \\
Ethnicity & & & \\
European & & $196(76.6)$ & \\
Indian & $3(1.2)$ & \\
Māori & $34(13.3)$ & \\
Other & & $(3.5)$ & \\
Pacific Island & & $14(5.5)$ & \\
Smoking & & $\mathbf{n} / 142(\%)$ & \\
Current & $33(23.2)$ & \\
Ex-smoker & & $84(59.2)$ & \\
Never-smoker & & $25(I 7.6)$ & \\
\hline
\end{tabular}

Abbreviations: FEV, forced expiratory volume; IQR, interquartile range; $P R$, pulmonary rehabilitation; SD, standard deviation.

programs in the past, and in this service, patients were not generally re-enrolled within 2 years unless they were on a lung transplant waiting list.

Thirty-five patients were referred after hospitalization for acute exacerbation of COPD, of whom 29 (83\%) were enrolled within 6 weeks. Of the 226 patients with complete attendance data, about half attended $>70 \%$ of the sessions. COPD was the main diagnosis for $212 / 256$ (83\%) of patients.

Attendance counts and proportions are shown in Table 2 by sex, ethnicity, and smoking status. The overall $P$-value for a difference in attendance rates by sex was 0.45 , by ethnicity 0.002 , and by smoking status 0.031 . Table 3 shows the comparisons between females and males, Europeans and other ethnic groups, and current smokers and other smoking groups.

There was no evidence of an association between age and FEV1\%, with rank-correlation coefficients of 0.09 $(\mathrm{N}=226, P=0.51)$ for age and $0.15(\mathrm{~N}=132, P=0.08)$ for FEV1\%. There was some evidence of an association between attendance counts and first 6MWT distance, with a longer distance associated with a higher number of attendances, rank-correlation $0.18(\mathrm{~N}=193, P=0.013)$. The relative rate of attendance was 1.007 (95\% CI 1.002 to 1.014$)$ per 10 meters further.

The paired difference in 6MWT was 35.3 meters ( $95 \%$ CI 25.0 to 45.6 ), $P<0.001$ (Table 4).
Table 2 Attendance counts and proportions by sex, ethnicity, and smoking status

\begin{tabular}{|c|c|c|c|}
\hline Variable & Mean (SD) & Median (IQR) & Min to $\max$ \\
\hline \multicolumn{4}{|l|}{$\overline{\text { Sex }}$} \\
\hline \multicolumn{4}{|l|}{ Attendance count } \\
\hline Female $\mathrm{N}=135$ & $10.0(5.2)$ & II (7 to I4) & 0 to 16 \\
\hline Male $\mathrm{N}=91$ & $10.6(5.3)$ & $13(7$ to 15$)$ & 0 to 16 \\
\hline \multicolumn{4}{|c|}{ Attendance proportion (\%) } \\
\hline Female $\mathrm{N}=135$ & $62.0(32.7)$ & $68.8(43.8$ to 87.5$)$ & 0 to 100 \\
\hline Male $\mathrm{N}=91$ & $66.3(33.3)$ & 81.3 (43.8 to 93.8$)$ & 0 to 100 \\
\hline \multicolumn{4}{|l|}{ Ethnicity } \\
\hline \multicolumn{4}{|l|}{ Attendance count } \\
\hline European $\mathrm{N}=70$ & $10.9(5.2)$ & $13(9$ to 15$)$ & 0 to 16 \\
\hline Māori $\mathrm{N}=33$ & $8.1(4.9)$ & $9(3$ to 12$)$ & 0 to 16 \\
\hline Pacific Island $\mathrm{N}=13$ & $6(4.9)$ & $5(I$ to $I I)$ & I to 15 \\
\hline Indian and other $\mathrm{N}=10$ & $10.9(4.7)$ & $13(7$ to 14$)$ & I to 16 \\
\hline \multicolumn{4}{|c|}{ Attendance proportion (\%) } \\
\hline European $\mathrm{N}=170$ & $68.4(32.3)$ & 81.3 (56.3 to 93.8$)$ & 0 to 100 \\
\hline Māori $\mathrm{N}=33$ & $50.4(30.6)$ & $56.3(18.8$ to 75$)$ & 0 to 100 \\
\hline Other $\mathrm{N}=8$ & $66.4(33.1)$ & 84.4 (40.6 to 87.5$)$ & 6.3 to 100 \\
\hline Pacific Island $\mathrm{N}=13$ & $37.5(30.8)$ & 31.3 (6.3 to 68.8$)$ & 6.3 to 93.8 \\
\hline \multicolumn{4}{|l|}{ Smoking status } \\
\hline \multicolumn{4}{|l|}{ Attendance count } \\
\hline Current $\mathrm{N}=3 \mathrm{I}$ & $7.0(5.5)$ & $8(1$ to 12$)$ & 0 to 16 \\
\hline Ex-smoker $\mathrm{N}=79$ & $10.5(5.3)$ & $12(8$ to 15$)$ & 0 to 16 \\
\hline Never-smoker $\mathrm{N}=23$ & $10.1(6.0)$ & $13(3$ to 15$)$ & 1 to 16 \\
\hline \multicolumn{4}{|c|}{ Attendance proportion (\%) } \\
\hline Current $\mathrm{N}=3 \mathrm{I}$ & $44.0(34.3)$ & $50.0(6.3$ to 75.0$)$ & 0 to 100 \\
\hline Ex-smoker $\mathrm{N}=79$ & $65.5(33.1)$ & 75.0 (50.0 to 93.8$)$ & 0 to 100 \\
\hline Never-smoker $\mathrm{N}=23$ & $63.3(37.5)$ & 81.3 (18.8 to 93.8$)$ & 6.3 to 100 \\
\hline
\end{tabular}

Abbreviations: IQR, interquartile range; $S D$, standard deviation.

Table 3 Relative rates of attendance by sex, ethnicity, and smoking status

\begin{tabular}{|c|c|c|}
\hline Comparison & Relative rate $(95 \% \mathrm{CI})$ & $P$-value \\
\hline Female versus male & $0.94(0.80$ to 1.10$)$ & 0.45 \\
\hline \multicolumn{3}{|l|}{ Ethnicity } \\
\hline European versus Māori & $\mathrm{I} .34$ (I.07 to I.73) & 0.014 \\
\hline European versus Pacific Island & $1.82(1.18$ to 2.80$)$ & 0.006 \\
\hline European versus other & $1.00(0.69$ to 1.45$)$ & 0.98 \\
\hline \multicolumn{3}{|l|}{ Smoking } \\
\hline Current versus ex-smoker & 0.67 (0.49 to 0.92$)$ & 0.012 \\
\hline Current versus never-smoker & 0.69 (0.47 to 1.02$)$ & 0.064 \\
\hline
\end{tabular}

Table 4 Six-minute walk test before (first) and after (second) PR

\begin{tabular}{llll}
\hline Variable & Mean (SD) & Median (IQR) & Min to max \\
\hline $\begin{array}{l}\text { Six-minute walk test } \\
\text { first (meters) N=203 }\end{array}$ & 332.1 (I24.0) & 335 (245 to 410$)$ & 35 to 702 \\
$\begin{array}{l}\text { Six-minute walk test } \\
\text { second (meters) N=14 I }\end{array}$ & $382.0($ (122.9) & $380(300$ to 467$)$ & 70 to 715 \\
$\begin{array}{l}\text { Six-minute walk test } \\
\text { second minus first } \\
\text { (meters) N=140 }\end{array}$ & $35.3(61.6)$ & $30.0(2.5$ to 67.5$)$ & -135 to 340 \\
\hline
\end{tabular}

Abbreviations: IQR, interquartile range; PR, pulmonary rehabilitation; $\mathrm{SD}$, standard deviation. 
Table 5 Attainment of BTS quality standards

\begin{tabular}{lll}
\hline No & $\begin{array}{l}\text { Summary of quality } \\
\text { statements for pulmonary }\end{array}$ & Compliance Comments \\
& Yehabilitation from BTS & \\
& $(2014)$ &
\end{tabular}

I Referral for pulmonary

rehabilitation:

a. People with COPD and self- $\quad Y$ reported exercise limitation (Medical Research Council dyspnea scale 3-5) are offered pulmonary rehabilitation.

b. If accepted, people referred for $Y$ pulmonary rehabilitation are enrolled to commence within 3 months of receipt of referral.

2 Pulmonary rehabilitation $Y$ programs accept and enroll patients with functional limitation due to other chronic respiratory diseases (for example, bronchiectasis, interstitial lung disease, and asthma) or COPD Medical Research Council dyspnea scale 2 if referred.

3 Referral for pulmonary rehabilitation after hospitalization for acute exacerbations of COPD:

a. People admitted to hospital Partial Some referred with acute exacerbations of COPD are referred for pulmonary rehabilitation at discharge.

b. People referred for pulmonary $\mathrm{N}$ rehabilitation following admission with acute exacerbation of COPD are enrolled within I month of leaving hospital.

4 Pulmonary rehabilitation $Y$ programs are of at least 6 weeks duration and include a minimum of twice weekly supervised sessions.

5 Pulmonary rehabilitation $Y$ programs include supervised, individually tailored and prescribed progressive exercise training, including both aerobic and resistance training.

6 Pulmonary rehabilitation $Y$ programs include a defined, structured education program.

7 People completing pulmonary N rehabilitation are provided with an individualized structured, written plan for ongoing exercise maintenance.
Not usually provided
Table 5 (Continued)

\begin{tabular}{|c|c|c|c|}
\hline No & $\begin{array}{l}\text { Summary of quality } \\
\text { statements for pulmonary } \\
\text { rehabilitation from BTS } \\
(2014)\end{array}$ & $\begin{array}{l}\text { Compliance } \\
\text { Y/N/partial }\end{array}$ & Comments \\
\hline 8 & $\begin{array}{l}\text { People attending pulmonary } \\
\text { rehabilitation have the outcome } \\
\text { of treatment assessed using as a } \\
\text { minimum, measures of exercise } \\
\text { capacity, dyspnea, and health } \\
\text { status. }\end{array}$ & Partial & $\begin{array}{l}\text { 6MWT routinely } \\
\text { measured. } \\
\text { St. George's } \\
\text { Respiratory } \\
\text { Questionnaire } \\
\text { handed out but } \\
\text { not scored. }\end{array}$ \\
\hline 9 & $\begin{array}{l}\text { Pulmonary rehabilitation } \\
\text { programs conduct an annual } \\
\text { audit of individual outcomes and } \\
\text { process. }\end{array}$ & $Y$ & \\
\hline 10 & $\begin{array}{l}\text { Pulmonary rehabilitation } \\
\text { programs produce an agreed } \\
\text { standard operating procedure. }\end{array}$ & Y & \\
\hline
\end{tabular}

Note: Data from British Thoracic Society. ${ }^{10}$

Abbreviations: 6MWT, 6-minute walk test; BTS, British Thoracic Society; COPD, chronic obstructive pulmonary disease; $Y$, yes; $N$, no.

This PR program complied with BTS quality standards ${ }^{8}$ apart from three areas of shortcoming as shown in Table 5. Although all referred patients who attended PR were enrolled within 3 months (256/256), those referred after admission to hospital with acute exacerbation of COPD were not enrolled within 1 month of discharge from hospital. Patients were not given an individualized plan for ongoing exercise maintenance. All patients who completed PR were routinely advised to continue community-based maintenance classes, which are not run by the hospital. This audit did not collect information on maintenance class attendance. Patients were given the St George's Respiratory Questionnaire to complete at enrolment in PR; this was commonly not completed or scored due to time pressure and low literacy rate. The cost of this service was approximately NZD 515 per patient enrolled, calculated from annual cost of the service (NZD 131,728) divided by the number of patients enrolled (256).

\section{Discussion}

This audit has shown that the CCDHB PR program enrolls $2 \%$ of the region's estimated number of patients with COPD. There was heterogeneity of disease severity, as measured by spirometry, in line with the hospital's policy to accept patients with symptomatic or functional limitation rather than specific pulmonary function test abnormalities. The overall mean improvement in 6MWT supports the efficacy of the program. The cost of this service was approximately NZD 515 (GBP 243) per patient enrolled, which compares favorably with UK published data of approximately GBP $600 .{ }^{16}$ The PR program attained seven out of ten BTS quality standards, 
revealing several areas for potential improvement. The recent ATS/ERS policy statement on enhancing implementation, use, and delivery of PR provides very useful suggestions. ${ }^{17}$

To increase referral rate to $\mathrm{PR}$, we have plans to increase awareness and knowledge of the benefits of PR in primary care and patient support groups to improve perception of PR effectiveness.

PR was declined by $20 \%$ of those offered with the main reason being "not interested". In other studies, the main reasons for low acceptance have been travel and reduced perceived benefit. ${ }^{18}$ Travel and transport difficulties were not the major barriers to attendance in this audit, as this has been addressed in recent years with the help of a hospital-funded support group "Whanau Care Services", which supports Māori and other patients to access health care.

Overall, the attendance rate was above average compared with other published audits; ${ }^{11-13}$ however, $<50 \%$ of the patients enrolled completed a PR program, using definition of completion as at least $75 \%$ sessions attended. ${ }^{19}$ Current smokers had lowest rates of attendance, as documented by others. ${ }^{20}$

Another concern in this region is the disparity of health of Māori and Pacific Islanders, who have an increased prevalence of COPD, bronchiectasis, and smoking. ${ }^{21,22}$ This audit confirmed that Māori and Pacific Island patients attended significantly fewer sessions, even with the extra support of Whanau Care Services. Levack et al have recently explored factors influencing uptake of PR by Māori with COPD in New Zealand, ${ }^{23}$ concluding that, to improve uptake, PR programs should consider cultural responsiveness and indigenous leadership.

This audit demonstrated some limitations of using St George's Respiratory Questionnaire as a quality of life status instrument in a busy PR program. The CCDHB PR program now uses the Clinical COPD Questionnaire ${ }^{24,25}$ and the Hospital Anxiety and Depression Scale, ${ }^{26}$ both able to be completed by patients unsupervised with time efficiency.

The key conclusion from the audit is that too few $(2 \%)$ eligible patients access PR programs in our region. To redress this will require enhanced referral and a significant increase in capacity. To increase capacity within the current budget, one option might be to shorten the PR course to 6 weeks. The optimal duration of a PR program is not known; meta-analysis has not been possible due to heterogeneity in program duration and outcomes. ${ }^{27} \mathrm{~A}$ recent Cochrane review also concludes that while the ideal length of a PR program is unknown, some patients improve with short courses, and recommends that a PR program should include at least 4 weeks of exercise training. ${ }^{4}$ The contribution of the education program remains uncertain and difficult to measure. If an 8-week course is daunting, a 6-week course might be more acceptable and realistic for patients, more achieving completion $(>75 \%$ attendance), thereby improving PR delivery.

A rolling system has many potential advantages, including early recruitment after acute exacerbation of COPD and increased program capacity. ${ }^{8}$ This has been supported by one study showing that a rolling program enrolled more patients, was as effective as a static program, and had more completers. ${ }^{28}$ Another potential innovative approach would be to offer patients PR sessions at times more convenient for those who are working or caring for others during the day.

This audit is limited by gaps in clinical data collection; incomplete attendance recordings and no recorded symptom assessment measurements. As a result of this audit, we have now developed an electronic database to record data on all patients referred to, and attending, PR. This will allow better assessment of outcomes at follow-up audit.

Given the overall importance of physical activity and self-efficacy as an outcome of PR, ${ }^{29}$ we plan to develop individualized structured written plans for ongoing exercise maintenance for all patients completing PR program. Our group is also looking at participation in a community singing group (Sing Your Lungs Out) as a way of sustaining the benefits of PR and also as an alternative way of delivering a PR program attractive to Māori and Pacific people.

\section{Conclusion}

This audit concurs with other international data that, despite being a cost-effective and clinically effective intervention for COPD and other chronic lung diseases, PR is greatly underutilized. The evidence-based results of PR research suggest that more resources should be directed to provide more PR programs for our communities. But even working within budget limitations, there are areas of PR delivery to be improved, and innovative approaches to be researched.

\section{Disclosure}

The authors report no conflicts of interest in this work.

\section{References}

1. Vestbo J, Hurd SS, Agustí AG, et al. Global strategy for the diagnosis, management, and prevention of chronic obstructive pulmonary disease. Am J Respir Crit Care Med. 2013;187(4):347-365.

2. Yohannes AM, Alexopoulos GS. Depression and anxiety in patients with COPD. Eur Respir Rev. 2014;23(133):345-349.

3. Shirtcliffe P, Weatherall M, Marsh S, et al. COPD prevalence in a random population survey: a matter of definition. Eur Respir J. 2007;30(2):232-239.

4. McCarthy B, Casey D, Devane D, Murphy K, Murphy E, Lacasse Y. Pulmonary rehabilitation for chronic obstructive pulmonary disease. Cochrane Database Syst Rev. 2015;23(2):CD003793. 
5. Williams S, Baxter N, Holmes $\mathrm{S}$, et al. IMPRESS guide to the relative value of interventions for people with COPD. Br Thoracic Soc Rep.2012;4(2).

6. Bourbeau J, Saad N. Integrated care model with self-management in chronic obstructive pulmonary disease: from family physicians to specialists. Chron Respir Dis. 2013;10(2):99-105.

7. Spruit MA, Singh SJ, Garvey C, et al. An official American Thoracic Society/European Respiratory Society statement: key concepts and advances in pulmonary rehabilitation. Am J Respir Crit Care Med. 2013;188(8):e13-e64.

8. Bolton CE, Bevan-Smith EF, Blakey JD, et al. British Thoracic Society guideline on pulmonary rehabilitation in adults. Thorax. 2013;68(Suppl2): ii1-ii30.

9. Alison J, Barrack C, Cafarella P. The Pulmonary Rehabilitation Toolkit on Behalf of The Australian Lung Foundation; 2009. Available from: www.pulmonaryrehab.com.au. Accessed May 5, 2016.

10. British Thoracic Society. Quality standards for pulmonary rehabilitation in adults. Br Thoracic Soc Reps. 2014;6(2):1-32

11. Desveaux L, Janaudis-Ferreira T, Goldstein R, Brooks D. An international comparison of pulmonary rehabilitation: a systematic review. COPD. 2015;12(2):144-153.

12. Levack WMM, Weatherall M, Reeve JC, Mans C, Mauro A. Uptake of pulmonary rehabilitation in New Zealand by people with chronic obstructive pulmonary disease in 2009. N Z Med J. 2012;125(1348): 23-33.

13. Steiner MC, Holzhauer-Barrie J, Lowe D, Searle L, Skipper E, Welham S, Roberts CM. Pulmonary Rehabilitation: Steps to Audit, Breathe Better. National Chronic Obstructive Pulmonary Disease (COPD); 2016. Available from: www.rcplondon.ac.uk/projects/national-COPD-auditprogramme-pulmonary-rehabilitation-workstream. Accessed May 5, 2016.

14. Celli BR, Decramer M, Wedzicha JA, et al. An official American Thoracic Society/European Respiratory Society statement: research questions in COPD. Eur Respir J. 2015;45(4):879-905.

15. Steiner MC, Roberts CM. Pulmonary rehabilitation: the next steps. Lancet Respir Med. 2016;4(3):172-173.

16. Griffiths TL, Phillips CJ, Davies S, Burr ML, Campbell IA. Cost effectiveness of an outpatient multidisciplinary pulmonary rehabilitation programme. Thorax. 2001;56(10):779-784.

17. Rochester CL, Vogiatzis I, Holland AE, et al. An Official American Thoracic Society/European Respiratory Society Policy Statement: enhancing implementation, use, and delivery of pulmonary rehabilitation. Am J Respir Crit Care Med. 2015;192(11):1373-1386.
18. Keating A, Lee A, Holland AE. What prevents people with chronic obstructive pulmonary disease from attending pulmonary rehabilitation? A systematic review. Chron Respir Dis. 2011;8(2):89-99.

19. Boutou AK, Tanner RJ, Lord VM, et al. An evaluation of factors associated with completion and benefit from pulmonary rehabilitation in COPD. BMJ Open Respir Res. 2014;1(1):e000051.

20. Sabit R, Griffiths TL, Watkins AJ, Evans W, Bolton CE, Shale DJ, Lewis KE. Predictors of poor attendance at an outpatient pulmonary rehabilitation programme. Respir Med. 2008;102(6):819-824.

21. Ministry of Health NZ. District Health Board Māori Health Plans Profiles and Needs Assessments; 2015. Available from: www.health. govt.nz/our-work/populations/maori-health/dhb-maori-health-plansprofiles-and-summaries. Accessed May 5, 2016.

22. Telfar Barnard L, Baker M, Pierse N, Zhang J. The Impact of Respiratory Disease in New Zealand: 2014 Update. Report for The Asthma Foundation New Zealand; 2014. Available from: www.asthmafoundation.org.nz/research/the-impact-of-respiratory-disease-in-new-zealand2014-update. Accessed May 5, 2016.

23. Levack WM, Jones B, Grainger R, Boland P, Brown M, Ingham TR. Whakawhanaungatanga: the importance of culturally meaningful connections to improve uptake of pulmonary rehabilitation by Māori with COPD - a qualitative study. Int J Chron Obstruct Pulmon Dis. 2016; 11(1):489-501.

24. van der Molen T, Willemse BWM, Schokker S, ten Hacken NHT, Postma DS, Juniper EF. Development, validity and responsiveness of the Clinical COPD Questionnaire. Health Qual Life Outcomes. 2003;1:13.

25. Kon SS, Dilaver D, Mittal M, et al. The clinical COPD questionnaire: response to pulmonary rehabilitation and minimal clinically important difference. Thorax. 2014;69(9):793-798.

26. Zigmond AS, Snaith RP. The hospital anxiety and depression scale. Acta Psychiatr Scand. 1983;67(6):361-370.

27. Beauchamp MK, Janaudis-Ferreira T, Goldstein RS, Brooks D. Optimal duration of pulmonary rehabilitation for individuals with chronic obstructive pulmonary disease - a systematic review. Chron Respir Dis. 2011;8(2):129-140.

28. Tomkinson J, Rossdale M, Tomkinson, JL Rossdale M. P47 Outcomes of static vs continuous rolling community pulmonary rehabilitation (PR) programmes. Thorax. 2010;65(Suppl 4):A97.

29. Spruit MA, Pitta F, McAuley E, ZuWallack RL, Nici L. Pulmonary rehabilitation and physical activity in patients with chronic obstructive pulmonary disease. Am J Respir Crit Care Med. 2015;192(8):924-933.
Clinical Audit

\section{Publish your work in this journal}

Clinical Audit is an international, peer-reviewed, open access journal focusing on the processes and outcomes of clinical audit in any area of healthcare. All aspects of patient care are addressed within the journal and practitioners from all disciplines are invited to submit their work. Areas covered include: Publication of audits; How an audit has changed practice; Submit your manuscript here: https://www.dovepress.com/clinical-audit-journal

\section{Dovepress}

Practical tips on how to do audits and to avoid pitfalls; How audits have changed patient care; Calls and justifications for new audits. The manuscript management system is completely online and includes a very quick and fair peer-review system, which is all easy to use. Visit http://www.dovepress. com/testimonials.php to read real quotes from published authors. 